\title{
Antagonistic properties of microogranisms associated with cassava (Manihot esculenta Crantz) products
}

\author{
Agarry, O.O.*, Akinyosoye, F.A., and. Adetuyi, F.C. \\ Department of Microbiology, Federal University of Technology, P.M.B. 704, Akure. \\ Ondo State,Nigeria
}

Accepted 22 November, 2004

\begin{abstract}
The antagonistic properties of indigenous microflora from cassava starch, flour and grated cassava were investigated using the conventional streak, novel ring and well diffusion methods. Antagonism was measured by zone of inhibition between the fungal plug and bacterial streak/ring. Bacillus species were more effective to inhibit the growth of Aspergillus niger, A. fumigatus, Fusarium moniliforme and Rhizoctonia sp. Pseudomonas fluorescens, Escherichia coli and Saccharomyces sp. inhibited the growth of $A$. niger, $A$. flavus and $F$. moniliforme. There were considerable variations in inhibitory activity. The zone of inhibition was more apparent in the novel ring method. Percentage inhibition increased to $78 \%$ in the Ring method and $62 \%$ in streak method after $168 \mathrm{~h}$ of incubation. Lactobacillus brevis, L. acidophilus and Bacillus subtilis inhibited the growth of E. coli and Staphylococcus aureus. Inhibition of the pathogenic microorganisms was probably due to the production of organic acids and bacteriocins.
\end{abstract}

Key words: Cassava product microflora, antagonism, bacteriocins, organic acids.

\section{INTRODUCTION}

Cassava (Manihot esculenta, Crantz) roots are processed into different products according to local customs and preferences. The products derived are high energy foods of excellent quality. Cassava, is however affected by fungi, bacteria, viral and virus-like and mycoplasma agent (IITA, 1993). Achievement of biocontrol measure through microorganisms that occur naturally in the field has been made a reality via antibiotics, bacteriocins and bacteriophage (Moore, 1983). The anti-microbial properties of microbes have therefore led to the characterization of various antimicrobial substances as organics acids (lactic acid and formic acids), diacetyl, and hydrogen peroxide alone or in combination (Piard and Desmazeaud, 1992). Other antimicrobial substances with antagonistic properties include biocides, sterilants, and probiotics. The production of specific protein or protein complexes, bacteriocin that inhibits some Gram positive bacteria, mainly homologous

*Corresponding author. E-mail: oluagarry@yahoo.com. species, some sphaeroplast of Gram negative bacteria and antifungal antibiotics also confirmed the possibilities of bio-competitive exclusion of pathogenic organisms from food. Therefore, the objectives of this paper were to investigate the antagonistic properties of isolates from cassava products and to characterize the inhibitory substance(s) of the isolates.

\section{MATERIALS AND METHODS}

Microbial cultures

The microorganims used in this investigation (Bacillus cereus, $B$. subtilis, B. pumilus, Escherichia coli, Klebsiella aerogenes, Lactobacillus acidophilus, Leuconostoc mesenteroides, Pseudomonas aeroginosa, P. fluorescens, Salmonella sp., Shigella flexneri, Staphylococcus aureus, Aspergillus flavus, A. fumigatus, A. niger, Candida sp., Fusarium moniliforme, F. nivale, Mucor mucedo, Neurospora sp., Penicillium sp, Rhizopus stolonifer, Trichoderma viridae, Rhizoctonia sp. and Saccharomyces sp.) were isolated from grated cassava, cassava flour and starch (Olowoyo et al., 2001). The organisms were maintained by routine culture on agar slants, stored at $4^{\circ} \mathrm{C}$ between transfers. At least two additional subcultures $\left(24 \mathrm{~h}, 25^{\circ} \mathrm{C}\right)$ were made in fresh medium before use in the experiment. 


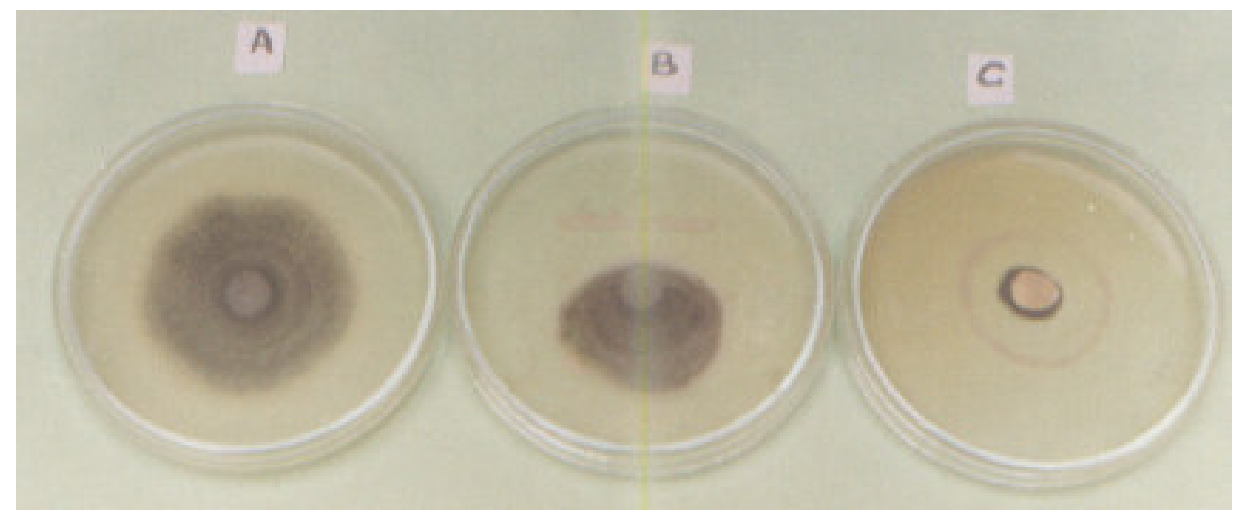

Figure 1. Antagonistic zone between Bacillus pumilus and Aspergillus niger. Photograph taken 5 days after inoculation. Codes: A, control; B, Fokkema/Conventional streak method; C, Concentric/Novel Ring bioassay.

\section{Detection of Antagonistic Activity}

For detection of antagonistic activity of bacterial isolates towards the growth of the fungal cultures, both Fokkema (1973) and Adetuyi and Cartwright (1985) methods were used. For the conventional streak method (Fokkema, 1973), $40 \mathrm{~mm}$ streak was made from 24 $\mathrm{h}$ - old culture of bacteria, $23 \mathrm{~mm}$ away from the centre of petridish. Using a $7 \mathrm{~mm}$ diameter sterile cork borer, the growing edge of a 4-day old fungal culture was aseptically cut and placed at the centre of the plate already inoculated with the test antagonist. Plates were incubated at $25^{\circ} \mathrm{C}$ and monitored for 7 days. Measurement of the percentage of inhibition and intercolony distance were taken daily.

For the Novel ring method of Adetuyi and Cartwright (1985), bacteria were cultured on nutrient agar plates into confluent growth. Prepared Malt Extract Agar plates were inoculated separately with concentric ring culture of the organism. The fungal plug $(7 \mathrm{~mm})$ was transferred aseptically into the centre of the plate already inoculated with the test antagonist. Plates were incubated at $25^{\circ} \mathrm{C}$ and monitored for 7 days. The measurement of the percentage of inhibition and intercolony distance were taken daily.

The well diffusion assay described by Schillinger and Lucke (1989) was used for the in-vitro test of antagonistic activities of bacterial isolates against other bacteria. Plates containing solidified Nutrient Agar $(20 \mathrm{ml}$ ) were overlaid with $10 \mathrm{ml}$ of soft Nutrient Agar and inoculated with $0.05 \mathrm{ml}$ of an overnight culture of test isolate. Four wells, three of the periphery and one at the centre, each $7 \mathrm{~mm}$ in diameter were made in the agar using cork borer and $0.1 \mathrm{ml}$ of culture supernatant of test bacterium were transferred into each well. The plates were incubated for $24 \mathrm{~h}$ at $25^{\circ} \mathrm{C}$, examined for clear inhibition zone around the well. The assay was carried out in duplicate for all the test organisms.

\section{Preparation of culture supernatants}

The test antagonist was grown in a Nutrient Broth (Oxoid) at $25^{\circ} \mathrm{C}$ for $24 \mathrm{~h}$. Bacteria cells were removed by centrifuging the cultures at $3900 \mathrm{rpm}$ for $30 \mathrm{~min}$. The supernatant was used immediately.

\section{Characterization of inhibitory substance(s)}

To characterize the inhibitory compounds produced by the bacterial isolates, their culture supernatants were assayed for organic acids, bacteriocins and hydrogen peroxide by having their culture supernatants' pH adjusted to 6.5 , with the addition of $1 \mathrm{~mol} \mathrm{NaOH}$; treated (concentration $1 \mathrm{mg} \mathrm{ml}^{-1}$ ) for $12 \mathrm{~h}$ at $37^{\circ} \mathrm{C}$, or with catalase (concentration $0.5 \mathrm{mg} \mathrm{ml}^{-1}$ ), respectively. Each treated supernatant $(0.1 \mathrm{ml})$ was transferred into a well at the periphery of the agar and the untreated culture supernatant $(0.1 \mathrm{ml})$ was transferred into the well at the centre. The presence or absence of inhibitory zones around the wells was determined after incubation for $24 \mathrm{~h}$ at $25^{\circ} \mathrm{C}$. The assay was conducted in duplicates.

\section{RESULTS AND DISCUSSION}

Bacillus species were more effective in inhibiting the growth of $A$. niger, $A$. fumigatus, $F$. moniliforme, Rhizoctonia sp. and E. coli (Figures 1-4). Clear zones of inhibition were maintained throughout in both streak and ring biosassay. Antagonism was measured by zone of inhibition between the fungal plug and bacterial streak/ring. There were considerable variation in inhibitory activity. The zone of inhibition was more apparent in the novel ring method. Percentage inhibition increased to $78 \%$ in the ring method and $62 \%$ in the streak after $168 \mathrm{~h}$ of incubation (Figures 7-8). The antagonistic activities of Bacillus species could be attributed to the production of endospores, the antagonists are more adapted to environmental extremes than the pathogens.

$P$. fluorescens inhibited the growth of $A$. niger (Figure 5). Fluorescent Pseudomonas sp. have been suggested to be an important natural antagonist of plant pathogens (Kloepper et al., 1980). L. brevis and $L$ acidophilus showed varying degrees of inhibitory ability against $E$. coli and $B$. subtilis, the radii of inhibition zones varied from 10.0 to $12.5 \mathrm{~mm}$. B. pumilus was the least effective in inhibiting the growth of $E$. coli $(8.6 \mathrm{~mm})$. On the other hand, Saccharomyces sp. inhibited the growth of $E$. coli and $S$. aureus. The radii of their inhibition zones ranged from 8.0 to $8.9 \mathrm{~mm}$. Lactobacillus sp. are not known to be strong inhibitors of Gram- negative bacteria (Tagg et al., 1976). This observation is in conformity 


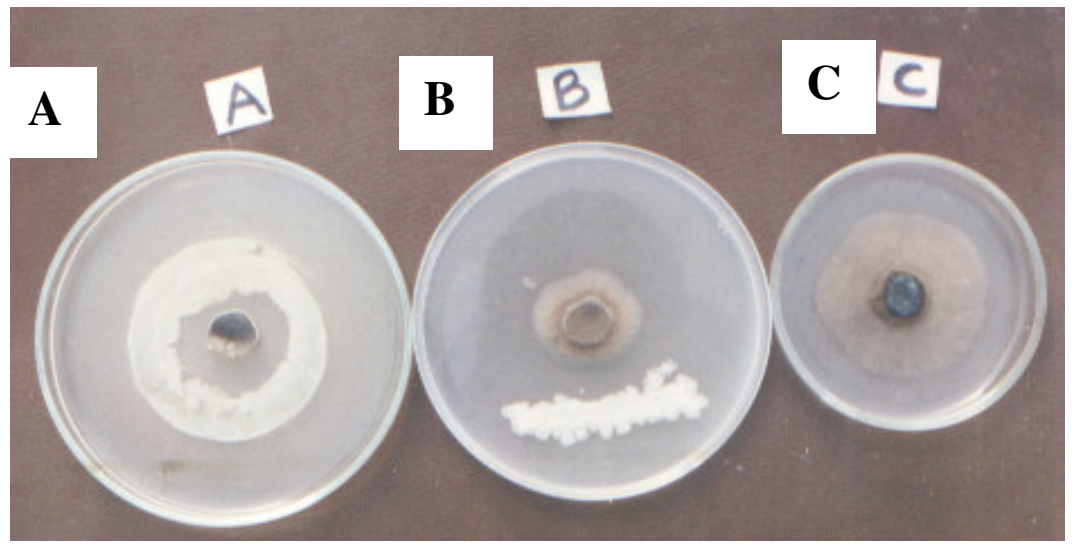

Figure 2. Antagonistic zone between Bacillus pumilus and $A$. fumigatus Photograph taken 5 days after inoculation. Codes: A, Concentric/Novel Ring bioassay; B, Fokkema/Conventional streak method; C, control.

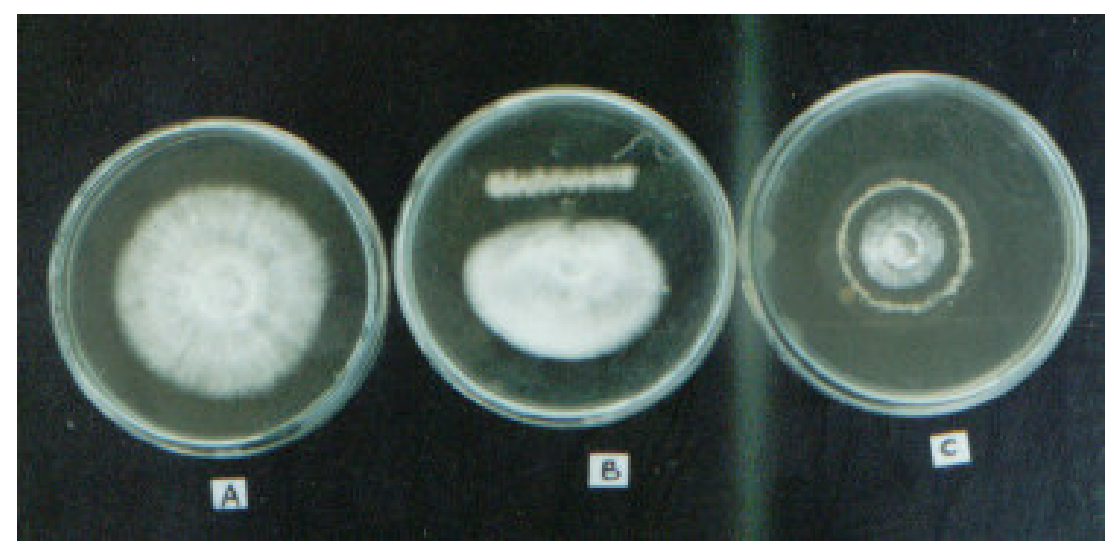

Figure 3. Antagonistic zone between Bacillus pumilus and Fusarium moniliforme. Photograph taken 5 days after inoculation. Codes: A, control; B, Fokkema/Conventional streak method; C, Concentric/Novel Ring bioassay.

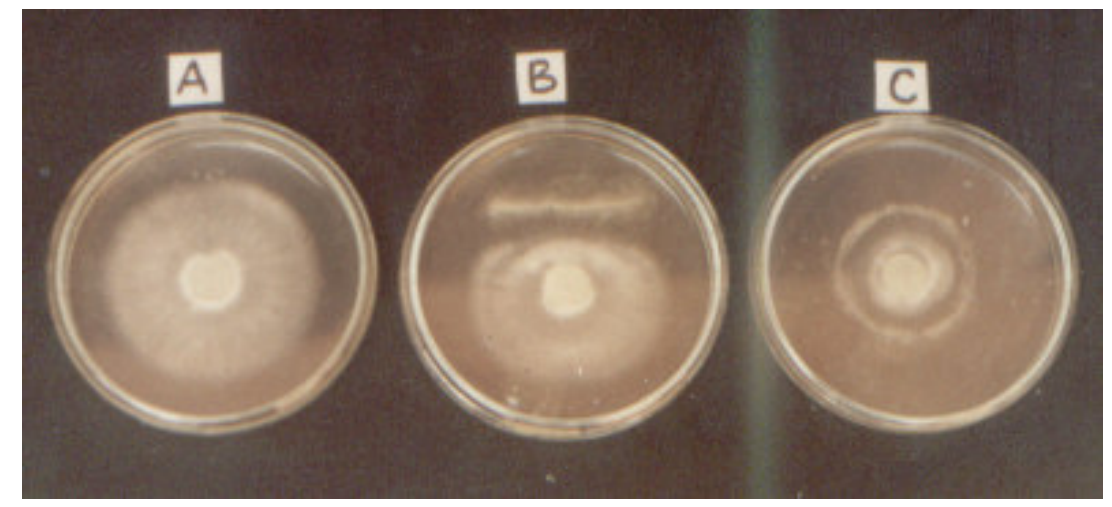

Figure 4. Antagonistic zone between Bacillus pumilus and Fusarium nivale. Photograph taken 5 days after inoculation. Codes: A, control; B, Fokkema/Conventional streak method; C, Concentric/Novel Ring bioassay. 


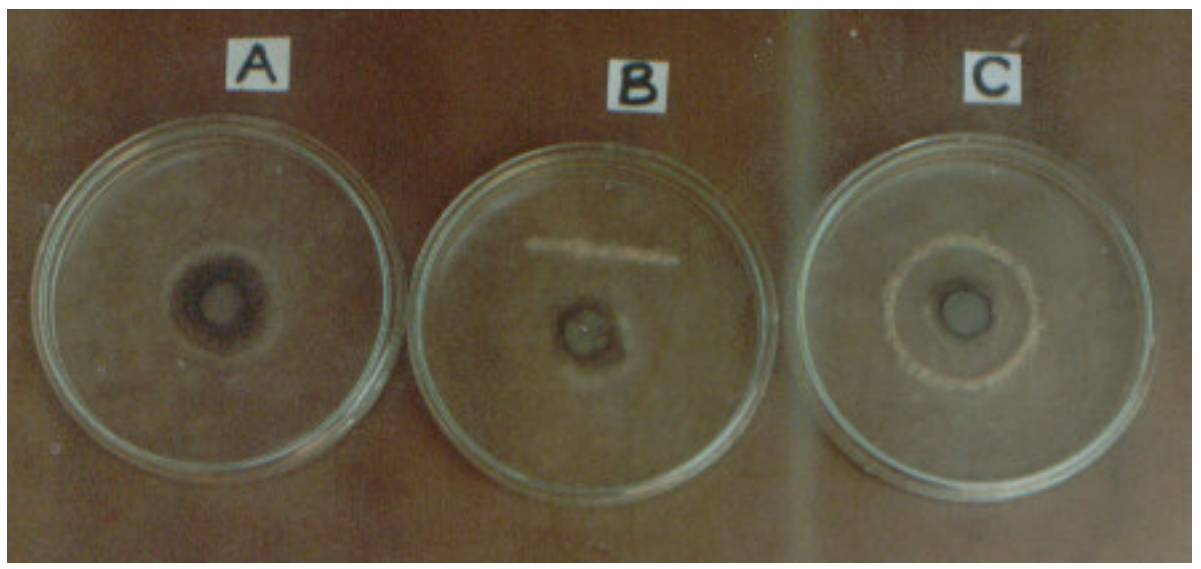

Figure 5. Antagonistic zone between Pseudomonas fluorescens and A.niger. Photograph taken 5 days after inoculation. Codes: A, control; B, Fokkema/Conventional streak method; C, Concentric/Novel Ring bioassay.

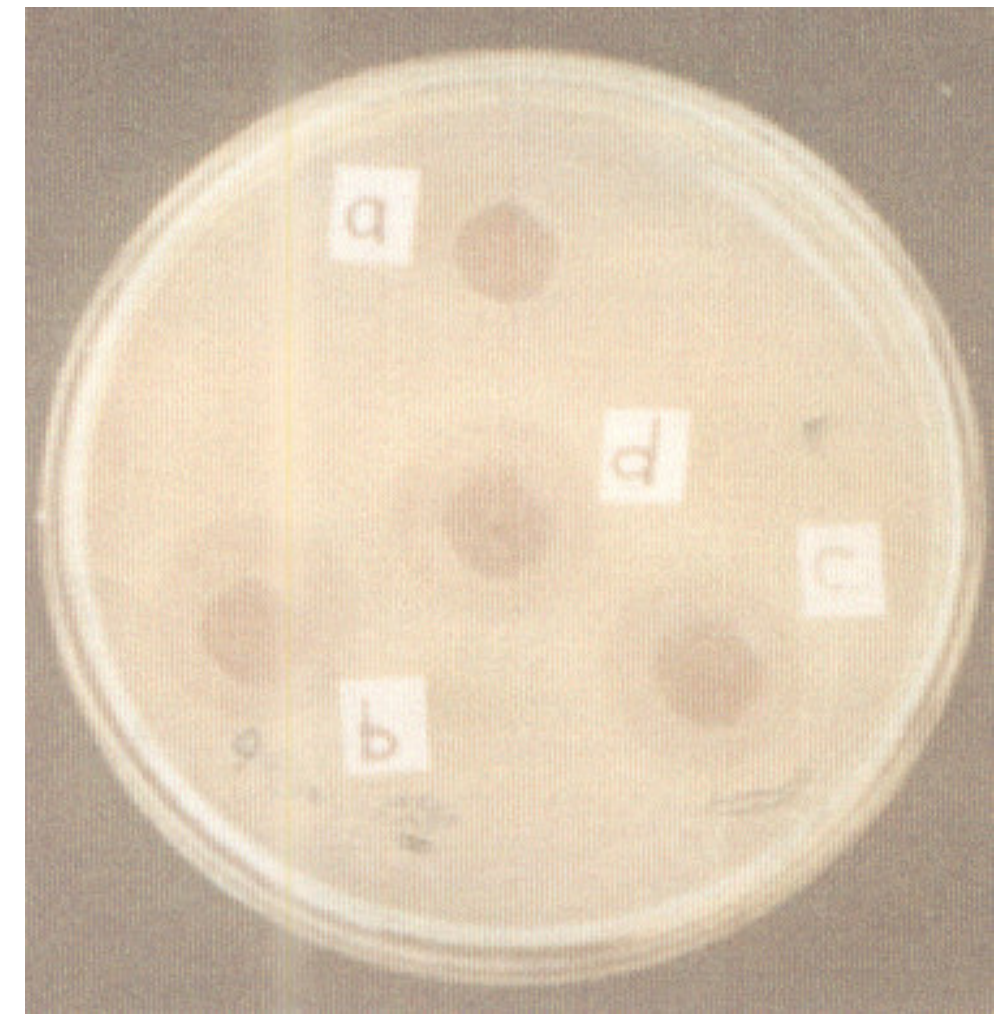

Figure 6. Antagonistic zones between Escherichia coli and treated culture supernatants of Bacillus pulmilus in agar well diffusion assay. A-well containing supernatant treated with $1 \mathrm{mg} / \mathrm{ml}$ trypsin. B-well containing supernatant treated with $\mathrm{NaOH}$. C-well containing supernatant treated with $0.5 \mathrm{mg} / \mathrm{ml}$ catalase. Dwell containing untreated culture supernatant (control). 


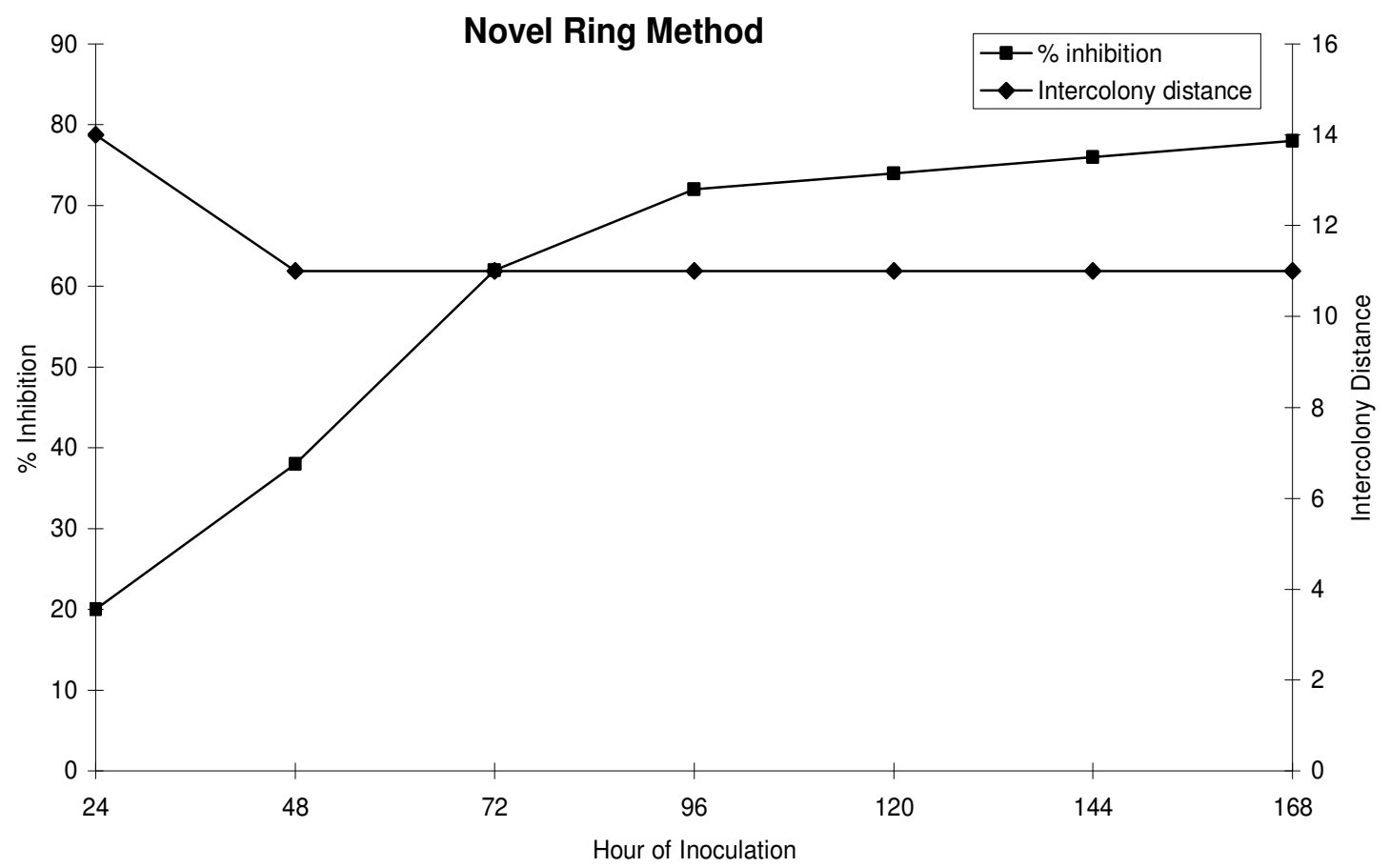

Figure 7. Effect of anatagonistic ability of Bacillus pulmelus on Fusarium nivale In terms of intercolony distance and percentage inhibiton of radial growth rate.

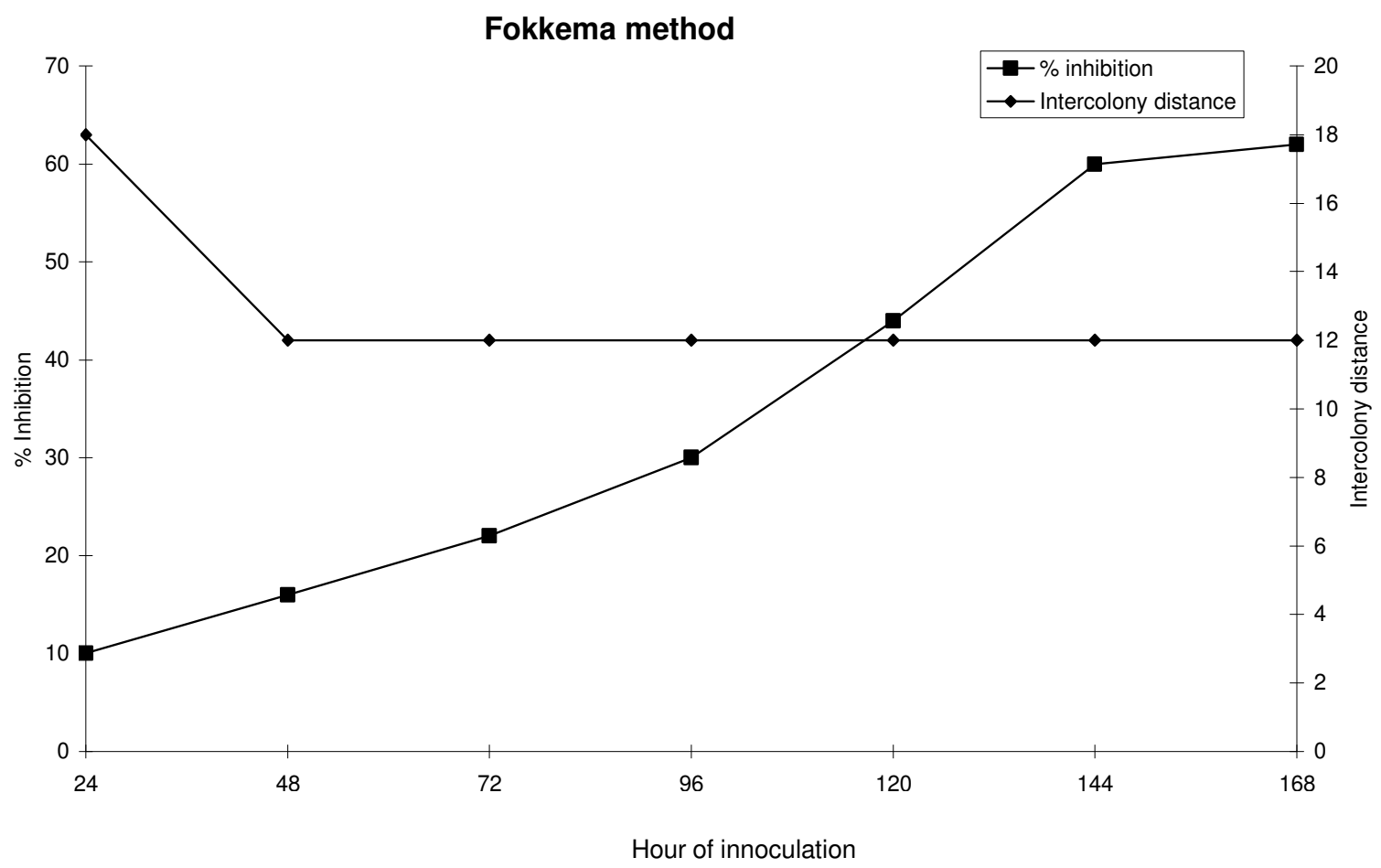

Figure 8. Effect of anatagonistic ability of Bacillus Pulmelus on Fusarium nivale in terms of intercolony distance and percentage inhibition of radial growth rate. 


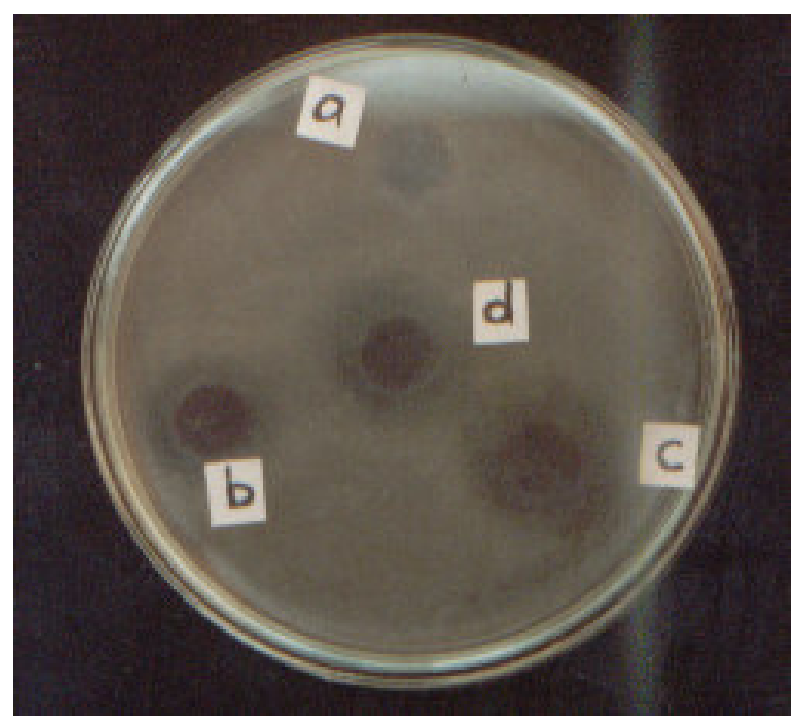

Figure 9. Inhibition of Staphylococcus aureus by treate supernatant of Bacillus pumilus in well diffusion assay. A-well containing supernatant treated with $1 \mathrm{mg} / \mathrm{ml}$ trypsin. B-well containing supernatant treated with $\mathrm{NaOH}$. C-well containing supernatant treated with $0.5 \mathrm{mg} / \mathrm{ml}$ catalase. D-well containing untreated culture supernatant (control).

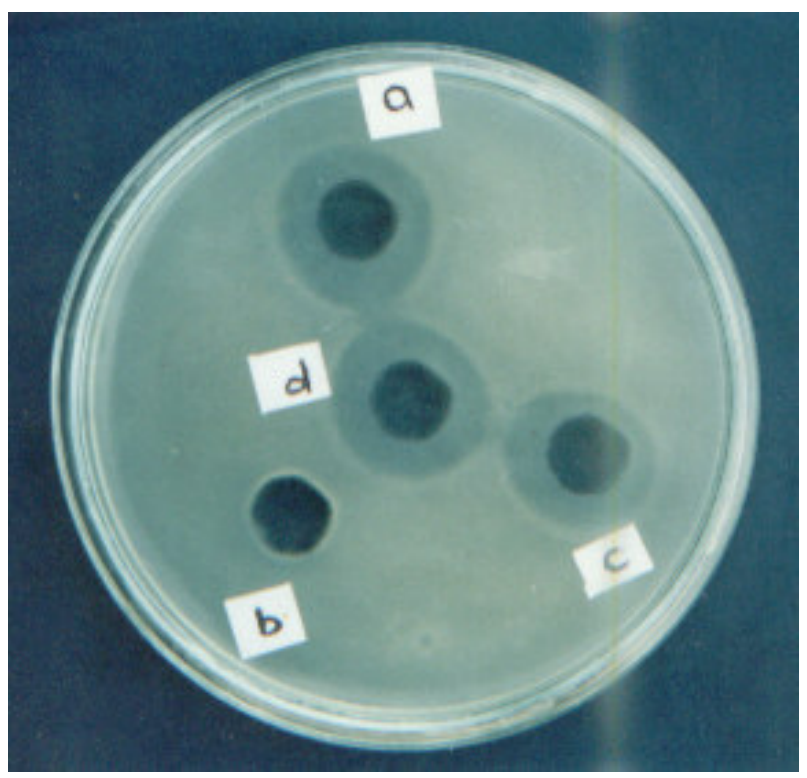

Figure 10. Inhibition of Escherichia coli by treated supernatant of Bacillus pumilus in a agar well diffusion assay. A-well containing supernatant treated with $1 \mathrm{mg} / \mathrm{ml}$ trypsin. B-well containing supernatant treated with $\mathrm{NaOH}$. C-well containing supernatant treated with $0.5 \mathrm{mg} / \mathrm{ml}$ catalase. D-well containing untreated culture supernatant (control).

with the reports of Gilliland and Speck (1977) that lactobacilli showed stronger antibacterial properties against Gram-positive bacteria (such as $S$. aureus). It has been suggested that lactobacilli block the adhering sites where pathogenic bacteria would attach. Their ability to inhibit the growth of pathogenic $E$. coli in the present investigation implies that the Lactobacillus strains not only attach to where the pathogens would adhere, but also produces some substance(s) to inhibit the growth of the pathogens.

The inhibitory zones remain unchanged when the culture supernatants were treated with catalase. This shows that inhibition was not caused by the action of hydrogen peroxide. Treatment of $L$. brevis and Saccharomyces sp. culture supernatants with trypsin also did not affect their inhibition activities. This suggests that inhibition was not due to the production of bacteriocin. No inhibitory zones were observed when $L$. brevis and Saccharomyces sp. culture supernatants were adjusted to $\mathrm{pH} 6.5$ which indicates that inhibition was due to the production of organic acids. Jin et al. (1996) reported that Lactobacillus sp. isolated from chicken intestine were able to inhibit the growth of pathogenic bacteria such as Salmonella and E. coli with the inhibitory activities probably due to the production of organic acids. The inhibiting ability of $B$. pumilus against $S$. aureus and $E$. coli was attributed to the production of bacteriocin (a polypeptide); there was no inhibitory zone observed when supernatants were treated with trypsin (Figures 9-10).

\section{REFERENCES}

Adetuyi, FC, Cartwright DW (1985). Studies on the antagonistic activity of bacteria endemic on cereal seed. I Quantification of antagonists activity. Ann. Appl. Biol. 107: 33-43.

Fokkema NJ (1973). The role of saprophytic fungi in antagonism against Dreschlera sorokiniana (Helminthosporium sativum) on agar plates and rye leaves with pollen. Physiol. Plant Path. 3: 15-105.

Gilliland SE, Speck ML (1977). Antagonistic action of Lactobacillus acidophilus toward intestinal and foodborne pathogens in association cultures. J. Food Protection 40: 820-823.

IITA Research Manual (1993) Cassava in Tropical Africa. A reference manual IITA Ibadan, Nigeria pp. 83-120

Jin LZ, Ho YW, Ali Abdullah N, Ong BK, Jalaludin S (1996). Adhension of Lactobacillus isolates to intestinal epithelial cells of chicken. Lett. Appl. Microbiol. 22: 229-232.

Kloepper JW, Leong J, Teintze M, Schroth MN (1980). Enhanced plant growth by siderophores produced by plant growth promoting rhizobacteria. Nature 286: 885-886.

Moore, LW (1983). Recent advances in the biological plant disease. Biological control in crop production (BARC Symposium 5 - George, C. Paparizased. Allanheld, Totoiva.

Olowoyo OO, Akinyosoye FA, Adetuyi FC (2001). Micro-organisms associated with some Cassava (Manihot esculenta, Crantz) Products. J. Res. Rev. Sci. (2): 10-14.

Piard JC, Desmazeaud MJ (1992). Inhibiting factors produced by lactic acid bacteria. 2. Bacteriocins and other antibacterial substances. Lait 72: 113-142.

Schillinger U, Lucke F (1989). Antibacterial activity of Lactobacillus strain isolated from meat. Applied and Environmental Microbiology 55: 1901-1906.

Tagg TR, Dajani AS, Wannamaker LW (1976). Bacteriocin of Grampositive bacteria. Bacteriol. Rev. 40: 722-756. 